\title{
Carbon-Doped Hexagonal Boron Nitride: Analysis as $\pi$-Conjugate Molecules Embedded in Two Dimensional Insulator
}

\author{
Wei Xie, Takashi Yanase *, Taro Nagahama and Toshihiro Shimada * \\ Division of Applied Chemistry, Faculty of Engineering, Hokkaido University, Kita 13 Nishi 8 Kita-ku, \\ Sapporo 060-8628, Japan; CREST, Japan Science and Technology Agency (JST), Tokyo, Japan; \\ xwwxyy11@qq.com (W.X.); nagahama@eng.hokudai.ac.jp (T.N.) \\ * Correspondence: yanase42@eng.hokudai.ac.jp (T.Y.); shimadat@eng.hokudai.ac.jp (T.S.) \\ Academic Editor: Jong-Sung Yu \\ Received: 1 January 2016; Accepted: 25 January 2016; Published: 29 January 2016
}

\begin{abstract}
We analyzed the electronic structures of carbon-doped hexagonal boron nitride, focusing on the comparison with the corresponding $\pi$-conjugate hydrocarbon molecules and odd-number substitution by first principle calculation. The band gaps are about the half that of the HOMO-LUMO gaps of corresponding hydrocarbons, except for the cis-butadiene structure in which aromatic hexagonal ring formation is important. Odd number doping makes metallic materials with very different work functions, depending upon the difference in $\mathrm{B}$ and $\mathrm{N}$ numbers, and has an expected application as electrodes for flexible devices.
\end{abstract}

Keywords: hexagonal boron nitride; carbon doping; electronic structure; DFT

\section{Introduction}

Two-dimensional carbon-based networks, such as grapheme [1] and $\mathrm{g}_{-} \mathrm{C}_{3} \mathrm{~N}_{4}[2-4]$, are gathering much attention due to high mobility carrier dynamics [5], sensitivity to molecular adsorbates [6], and photocatalytic activities [2-4], etc. Graphene and monolayer hexagonal boron nitride (h-BN) [7,8] are two end members of carbon-based two-dimensional systems. They have similar structures with distinctly different electronic structures; graphene has zero-gap and h-BN is a wide gap semiconductor. It is, therefore, expected that the mixture of the graphene and monolayer h-BN will become semiconductors with band gap values tunable by compositions. Synthetic attempts by chemical vapor deposition using well-defined synthesized molecules have started [9] and surface scientific techniques, such as scanning tunneling microscopy/spectroscopy, are revealing the relationship between the structure and the electronic properties $[10,11]$. Theoretical approaches have also been made from the association with graphene nanoribbons and two dimensional quantum dots [12-25]. The results of the previous studies can be summarized as follows: (1) C-C bonds are more stable than C-N or C-B bonds, and carbon atoms tend to segregate. (2) The effect of carbon doping in h-BN extends to three atoms distance [12-19]. In other words, the electronic structure of the doped carbon domains will be isolated in terms of electronic conduction if the mutual distance is beyond this range. It is an intriguing difference from organic semiconductors as discussed in this paper [12,16,17,19-21]. (3) The band gap values, and even the work function, are tunable by changing the composition [22]. (4) Some structures show magnetism (ferromagnetic or antiferromagnetic coupling within or beyond the domains) $[16,19,23,24]$. These features are exciting enough to proceed with more detailed studies. The missing points in the previous studies are as follows. (i) Although the C-doped structures have resemblance with $\pi$-conjugated molecules, the difference between the C-doped $\mathrm{h}$-BN and molecules in the vacuum have not been analyzed. (ii) The previous studies were mainly on substituting the same 
numbers of $\mathrm{B}$ and $\mathrm{N}$ atoms to carbon atoms. Unevenly substituted structures have not been studied in detail.

In this paper, we present a detailed analysis of the C-doped h-BN from the viewpoint that has not been treated previously. We focus on the resemblance and difference of carbon doped h-BN monolayers and corresponding organic $\pi$-electron systems by first principle calculation. Additionally, electronic properties of unevenly-doped structures are studied in detail. Based on the results, we will propose that the carbon-doped h-BN can be band gap-tunable semiconductors in the case of even-number doping, and that work function-tunable metallic electrode in the case of odd-number doping.

\section{Materials and Methods}

All the simulations in this work were carried out on the Quantum-Espresso programs [25] with the version of 5.1 which is based on density-functional theory (DFT), plane wave, and pseudopotentials. DFT was carried out with the exchange-correlation energy treated by the Perdew-Burke-Ernzerhof (PBE) functional based on the generalized gradient approximation (GGA) [26]. Ultrasoft pseudopotentials [27] were used to describe the ionic cores, and the electron wave function was expanded in plane waves with the cut-off energy of 50 Ry for the geometry optimization and properties calculations. The mono-layered hybrid structures of $C_{x} B_{y} N_{z}$ were modeled by a 4 $\times 4$ h-BN supercell with 32 atoms. More than $10 \AA$ An vacuum space as periodic boundary conditions avoids interactions between the layers in two neighboring cells. The atom positions were optimized until the forces on each ions converged in 0.0001 atomic units (a.u.) and the energy was converged in 0.00001 a.u. Brillouin zone integration was calculated as a sum over special k points of $9 \times 9 \times 1$ using the Monkhost-Pack scheme [28] for geometry optimization and total energy calculations. Work functions were calculated from the slab average of the potential and the Fermi energy as described in [29].

Electronic structures of carbon moiety (isolated molecules) were calculated by Gaussian 09W using DFT with PBE functional and 6-311G+ basis sets. Their structures were optimized by removing $\mathrm{B}$ and $\mathrm{N}$ atoms in the above structures and terminating the dangling bonds by hydrogen atoms.

\section{Results and Discussion}

\subsection{Consistency with Previous Results}

First, the structures of graphene and mono-layered hexagonal BN (h-BN) were optimized to check the correctness of the calculation. The calculated C-C bonding length in graphene is $1.419 \AA$, which is consistent to the reported result of $1.420 \AA$ [30]. The calculated B-N bonding length with the value of $1.448 \AA$ also shows the high consistency to reported results of $1.45 \AA$ [15]. The cohesive energies of graphene and mono-layered h-BN are $8.98 \mathrm{eV}$ and $8.56 \mathrm{eV}$, respectively. These large values are consistent with the previous report [31] and proved the high stability of graphene and h-BN. The calculated band gap of mono-layer h-BN is $4.17 \mathrm{eV}$, which is in agreement to earlier reports [31]. In addition, the band structure of graphene also agrees well with the published results [32] with a contact point at Fermi level which is located at high symmetry K-point.

We also examined the energy difference between the structures shown in Figure 1 with the same number (two) of carbon atoms. The relative total energy of each structure is written in Figure 1. The structure with the minimum number of $\mathrm{C}-\mathrm{B}$ and $\mathrm{C}-\mathrm{N}$ bonds gives the lowest energy. This is also consistent with the previous reports [12-24,33]. 


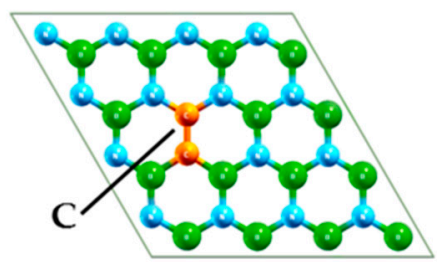

(a) reference

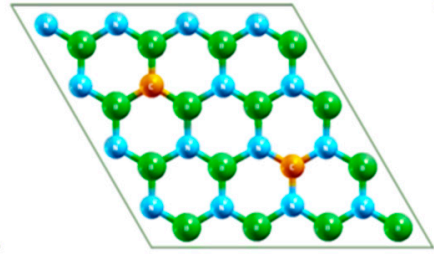

(b) $+0.04 \mathrm{eV} /$ atom

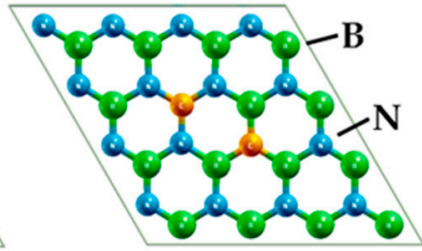

(c) $+0.07 \mathrm{eV} /$ atom

Figure 1. Relative energies of the $\mathrm{h}-\mathrm{B}_{16} \mathrm{~N}_{16}$ doped with two carbon atoms. (a) lowest energy configuraton; (b) two atoms separation; (c) four atoms separation.

\section{2. "Molecular-Doped" $h-B N$}

Figure 2 shows the optimized structure of carbon doped h-BN with various carbon content and topologies calculated in the present research. Each structure is named after corresponding $\pi$ - conjugate molecules. Some of them with large carbon content are directly connected with the carbons in the next cell.

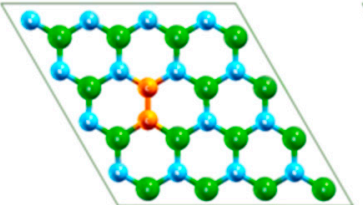

ethylene

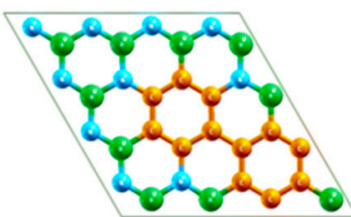

biphenyl

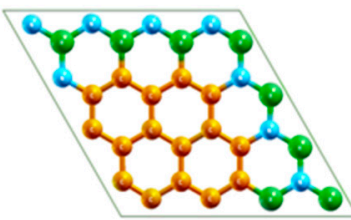

pyrene

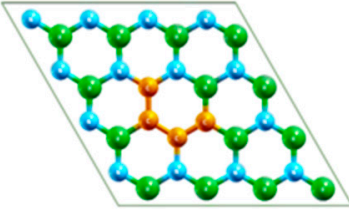

cis-butadiene

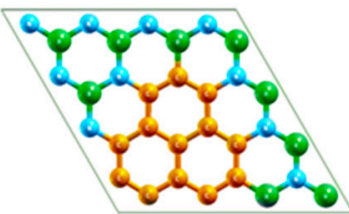

N-rich phenalenyl

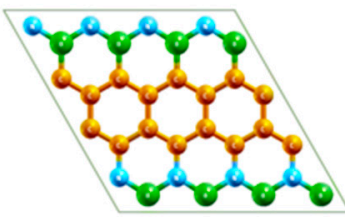

nanoribbon

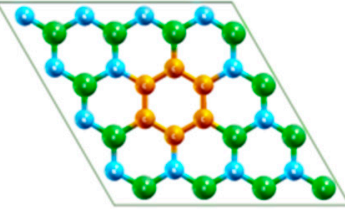

benzene

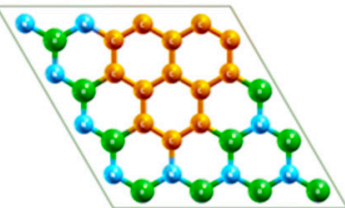

B-rich phenalenyl

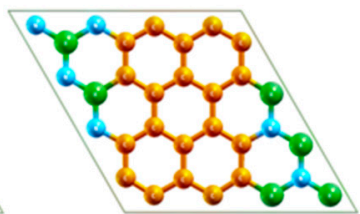

perylene

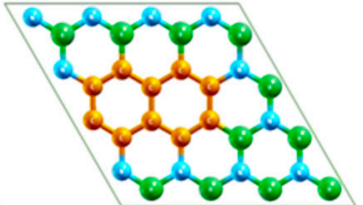

naphthalene

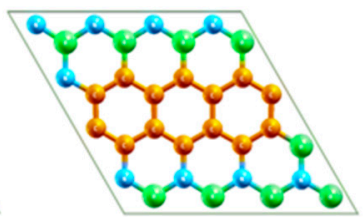

anthracene

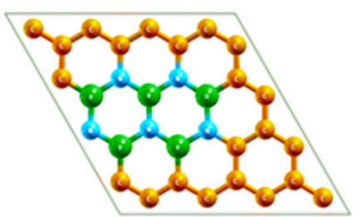

BN-naphtalene

Figure 2. Structure of the carbon-doped h-BNs analyzed in this work. They are named after corresponding organic molecules.

Figure 3 shows the $\mathrm{C}-\mathrm{C}$ bond length of these structures as a function of carbon content. Carbon content is shown as the number in an extended unit cell of $(\mathrm{BN})_{16}$ and, so, the maximum number is 32 . The C-C bond is shortened to $1.357 \AA$ in "ethylene", but increases in "butadiene" $(1.382 \mathrm{~A})$ and reaches a saturated value of $\sim 1.42 \AA$, which coincides with that of graphite, beyond the carbon content $6 / 32$. 


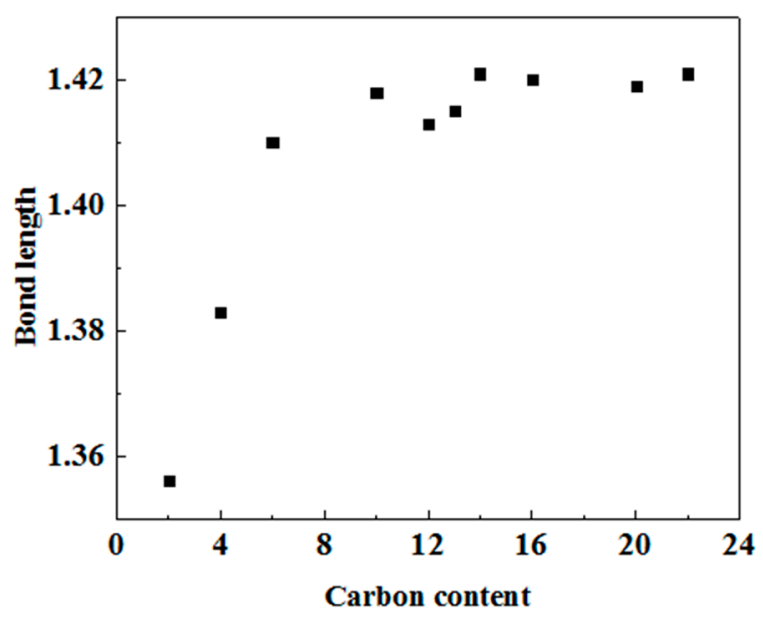

Figure 3. Average $\mathrm{C}-\mathrm{C}$ bond length of carbon content.

Figure 4 shows the band gap values of C-doped h-BN as a function of carbon content. The band gap values show significant decrease as the carbon content increase from the $3.23 \mathrm{eV}$ of "benzene" to the $0.983 \mathrm{eV}$ of "BN-Naphthalene", which is a smaller value of band gap than bulk silicon $(1.17 \mathrm{eV})$. This result indicates a theoretical possibility of replacing silicon in some applications in which band gap values are important. Furthermore, these carbon-doped h-BN structures have a direct band gap at the $\Gamma$ point, which would be an advantage for optical applications when compared with the bulk silicon.

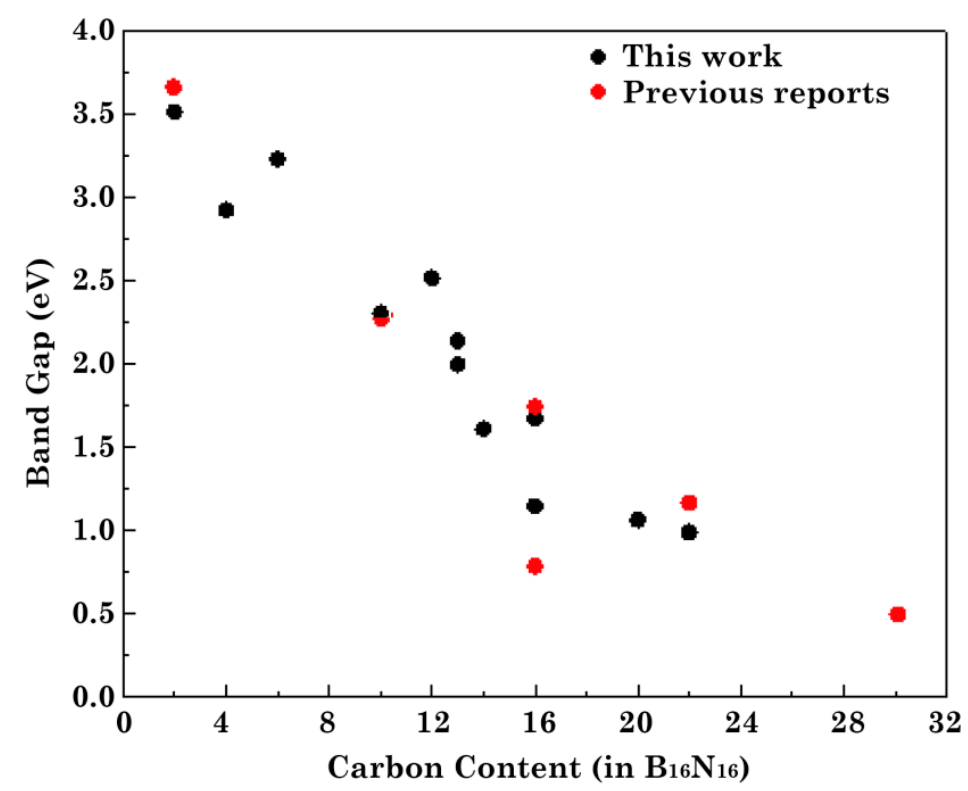

Figure 4. Band gap values as a function of carbon content in $\mathrm{B}_{16} \mathrm{~N}_{16}$. The results of previous works [12-24] are added.

The difference of the band gap values with the same carbon content is due to the different topologies or isomers, which is well known in organic semiconductor molecules. Additionally, direct interconnection beyond the periodic supercell lowers the band gap. Here, we examined the effect of the surrounding $\mathrm{BN}$ lattice in this materials system by comparing the $\mathrm{C}_{\mathrm{x}}(\mathrm{BN})_{\mathrm{y}}$ system with corresponding $\mathrm{C}_{\mathrm{x}} \mathrm{H}_{\mathrm{z}}$ molecules. Figure 5 shows the ratio between the band gap of $\mathrm{C}_{\mathrm{x}}(\mathrm{BN})_{\mathrm{y}}$ and HOMO-LUMO gap of corresponding $\mathrm{C}_{x} \mathrm{H}_{z}$ molecules. Most of the ratio ranges $0.46-0.52$ for the structures below $\mathrm{C}<16$, in which the carbon islands are not connected beyond the periodic cell. It is surprisingly constant 
despite the distance between the carbon islands not being uniform. The exception is butadiene (carbon content $=4 / 32$ ), which shows the ratio of 0.68 .

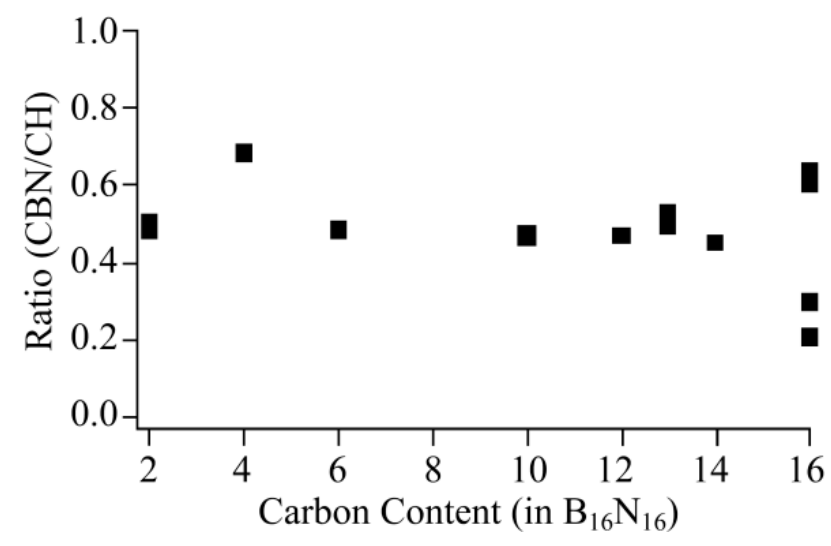

Figure 5. Ratio between bandgap of carbon doped h-BN and HOMO-LUMO gap of corresponding hydrocarbon molecules. Note that the "Carbon Content" axis shows half of that in Figure 4.

The reason for the discrepancy of butadiene is explained by Figure 6. We compare the HOMO (Figure 6a-c) and LUMO (Figure 6d-f) of $\mathrm{C}_{4} \mathrm{H}_{6}, \mathrm{C}_{4} \mathrm{~B}_{10} \mathrm{~N}_{10} \mathrm{H}_{12}$ (butadiene embedded coronene-like BN) and $\mathrm{C}_{4} \mathrm{BNH}_{6}$. The carbon atoms in $\mathrm{C}_{4} \mathrm{~B}_{10} \mathrm{~N}_{10} \mathrm{H}_{12}$ is located at the left part of the central hexagonal ring. The center hexagonal ring of (b) and (e) resembles (c) and (f), respectively, which shows the electronic structure of $\mathrm{C}-\mathrm{B}-\mathrm{N}$ can be well represented by the $\mathrm{C}_{4} \mathrm{BNH}_{6}$ molecule. By comparing the cis-butadiene and the $\mathrm{C}_{4} \mathrm{BNH}_{6}$ molecule, we notice that the $\mathrm{HOMO}$ and LUMO wavefunctions of $\mathrm{C}_{4} \mathrm{BNH}_{6}$ are composed of conjugate $\mathrm{p}_{\mathrm{z}}$-orbitals (p-orbitals perpendicular to the molecular plane) of $\mathrm{B}$, $\mathrm{N}$, and $\mathrm{C}$. The different electronegativity of $\mathrm{B}$ and $\mathrm{N}$ makes the HOMO higher and LUMO lower, and results in the HOMO-LUMO gap greater than that is expected from other geometries.

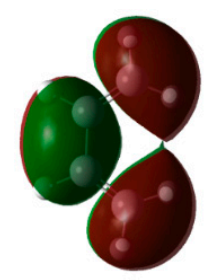

(a)

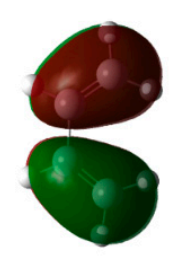

(d)

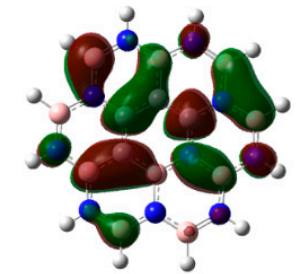

(b)

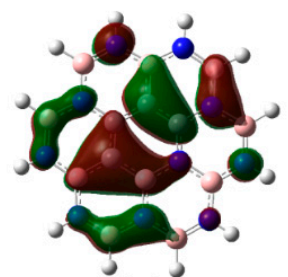

(e)

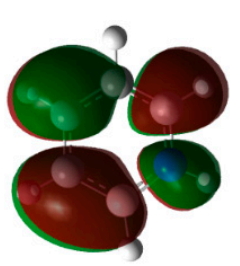

(c)

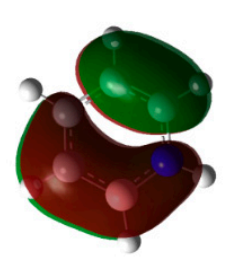

(f)

Figure 6. LUMO (a-c) and $\mathrm{HOMO}(\mathbf{d}-\mathbf{f})$ of butadiene, $\mathrm{C}_{4} \mathrm{~B}_{10} \mathrm{~N}_{10} \mathrm{H}_{12}$, and $\mathrm{C}_{4} \mathrm{BNH}_{6}$.

\subsection{Odd Number C-Doping_- "Phenalenyl-Embedded" in BN}

Finally we analyze the odd number C-doping. In this case, it is inevitable to replace B and N atoms unevenly. We focus on a motif of the recently-synthesized stable radical molecule "phenalenyl" [33-37]. There are two choices: C-atoms replace more B ("N-rich phenalenyl") or C-atoms replace more $\mathrm{N}$ ("B-rich phenalenyl"). Their band structures are plotted in Figure 7. It should be noted that these 
structures are metallic due to the odd number of $\pi$-electrons. The band dispersion of HOMO and LUMO levels are substantially large, around $1 \mathrm{eV}$ for both. This means that this structure can be used as metallic electrodes for flexible electronics. In "N-rich phenalenyl", LUMO (conduction band) crossed the Fermi level while in "B-rich phenalenyl", HOMO (valence band) crossed the Fermi level. In other words, "N-rich phenalenyl" and "B-rich phenalenyl" are n-type and p-type, respectively. The work function of N-rich and B-rich phenalenyl were $3.01 \mathrm{eV}$ and $4.88 \mathrm{eV}$, respectively.

These unique band structures can be understood as follows. In pristine h-BN, empty $\mathrm{p}_{\mathrm{z}}$-orbitals of $\mathrm{B}$ atoms make conduction band (LUMO) while filled $\mathrm{p}_{\mathrm{z}}$-orbitals of $\mathrm{N}$ atoms make valence bands. A carbon atom has one electron more than a B atom and one electron less than a $\mathrm{N}$ atom. When one more $\mathrm{B}$ atom is replaced by a $\mathrm{C}$ atom in "N-rich phenalenyl", one electron will be left in the conduction band to make an "n-type" band structure. The opposite reasoning is applied for "B-rich phenalenyl", in which one more $\mathrm{N}$ atom is replaced by a $\mathrm{C}$ atom, to make "p-type" band structure. These features are totally different from graphene, in which the band gap between HOMO and LUMO diminishes to zero at the K-point due to the symmetry of the $\pi$-electron network.

The atomic orbital expansions of the HOMO and LUMO bands were analyzed and shown in Figure 8. The upper panel of Figure 8 shows the (a) HOMO and (b) LUMO of "N-rich phenalenyl". The LUMO band, which crosses the Fermi level, was almost localized at $\mathrm{C}$ and $\mathrm{N}$ atoms, except for the $\mathrm{C}-\mathrm{N}$ bonds. The LUMO figure indicated that the effect from free electrons supplied by $\mathrm{C}$ atoms was dispersed into the carbon and nitrogen atoms. The HOMO band of "N-rich phenalenyl" was localized among the whole $\mathrm{p}_{\mathrm{z}}$-orbitals of $\mathrm{C}$ atoms and contributions from surrounding $\mathrm{B}$ and $\mathrm{N}$ are small.

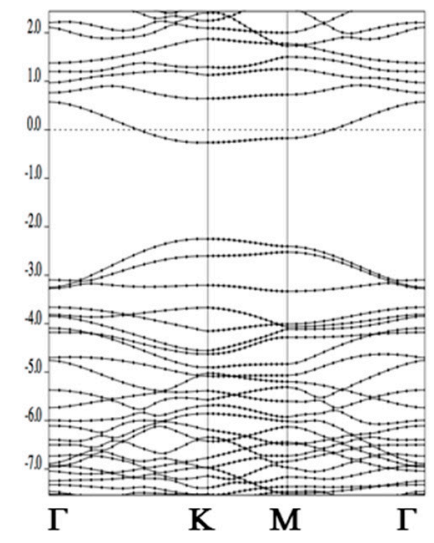

(a)

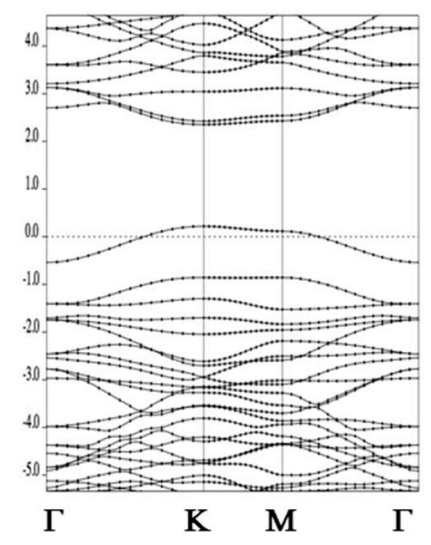

(b)

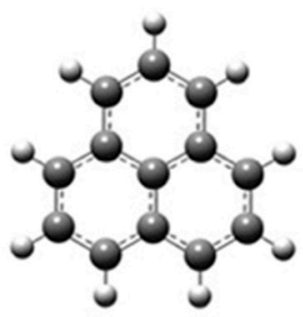

(c)

Figure 7. The band structures of "phenalenyl" doped h-BN. (a) "N-rich phenalenyl", seven boron atoms and six nitrogen atoms were replaced by carbon atoms. (b) "B-rich phenalenyl", six boron atoms and seven nitrogen atoms were replaced by carbon atoms. Energy zero are Fermi energies; (c) shows the structure of "phenalenyl" $\left(\mathrm{C}_{13} \mathrm{H}_{9}\right)$.

The lower panel of Figure 8 shows the (c) HOMO and (d) LUMO of "B-rich phenalenyl". Unlike the "N-rich phenalenyl", the HOMO band of "B-rich phenalenyl", which crossed the Fermi level, almost come from the $\pi$-bonds between the outermost $C$ and surrounding $B$ atoms. $B$ atoms in pristine h-BN usually bonded with the nearest three $\mathrm{N}$ atoms with $\sigma$-bonds and without $\pi$-bonds. When an $\mathrm{N}$ atom is replaced by a $\mathrm{C}$ atom, because the energy of $\mathrm{p}_{\mathrm{z}}$-orbital of the $\mathrm{C}$ atom is lower than that of the $\mathrm{N}$ atom, one electron from $\mathrm{C}$ will become delocalized among the outermost $\mathrm{C}$ and surrounding $\mathrm{B}$ atoms. Indeed $\mathrm{C}-\mathrm{B}$ bond length is the longest in this geometry among those examined in this study. On the other hand, LUMO is localized among $\mathrm{C}$ atoms. 

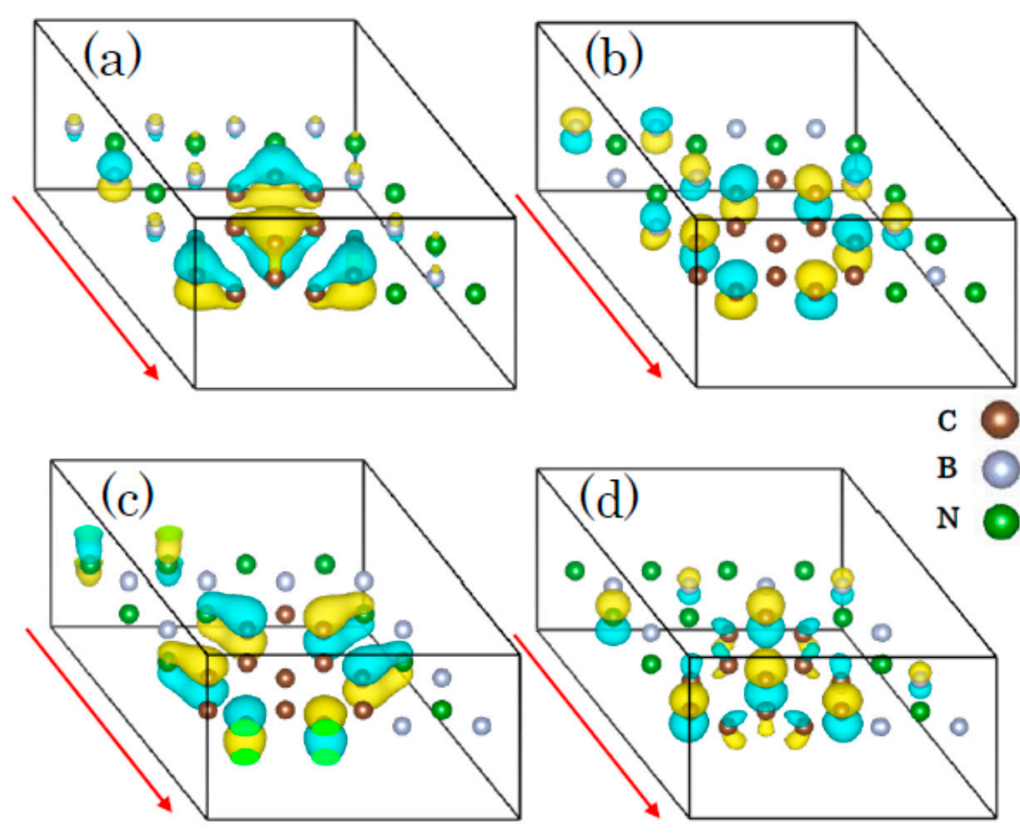

Figure 8. (a) HOMO and (b) LUMO of "N-rich phenalenyl", and (c) HOMO and (d) LUMO of "B-rich phenalenyl".

The electronic structures of these "Phenalenyl" embedded h-BN structures were analyzed further by using the total DOS as shown in Figure 9. A DOS peak crossed the Fermi level. HOMO and LUMO were mainly contributed by the $\mathrm{p}_{\mathrm{z}}$-orbital of carbon as discussed above.

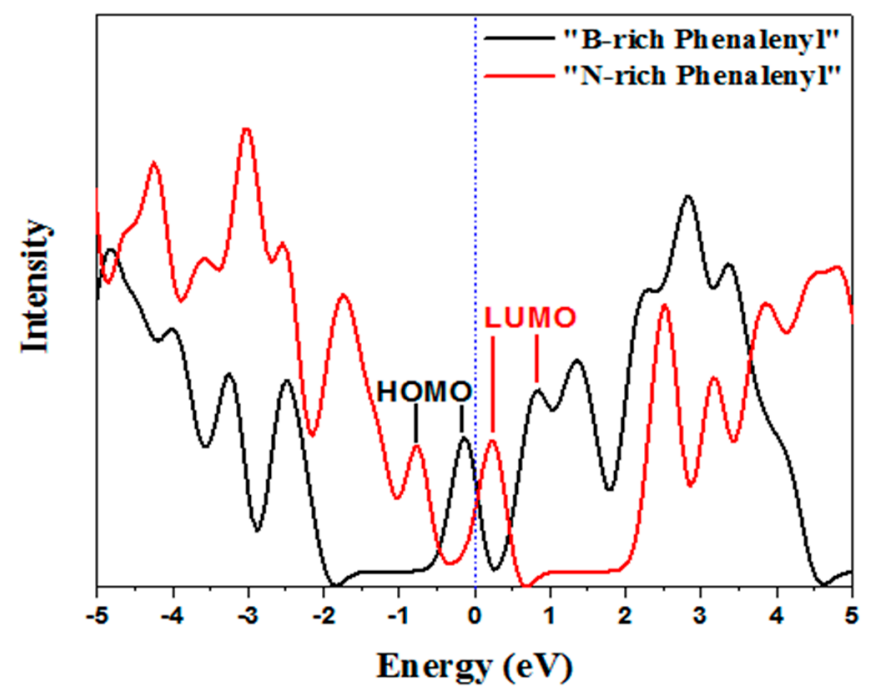

Figure 9. The DOS of the "B-rich Phenalenyl" (black curve) and "N-rich phenalenyl" (red curve).

\section{Conclusions}

Electronic structures of carbon-doped h-BN have been calculated. The focus points of this paper are the comparison between the corresponding $\pi$-conjugate hydrocarbon molecules and odd-number substitutions. The band gap values are about half that of the HOMO-LUMO gap of corresponding hydrocarbons, except for the butadiene structure, in which aromatic hexagonal ring formation is important. This result indicates that the analogy with organic molecules is effective to design the electronic functions of carbon-doped h-BN. Odd number doping makes metallic materials with very 
different band gap values. Those materials will find applications as electrodes for flexible devices, if the B-N ratio is controlled in the synthesis [38-40].

Author Contributions: Wei Xie did main calculation and analysis as a part of his dissertation research. Takashi Yanase and Taro Nagahama essentially contributed in discussion and in preparing the manuscript. Toshihiro Shimada planned the research and conducted additional calculations.

Conflicts of Interest: The authors declare no conflict of interest.

\section{References}

1. Novoselov, K.S.; Geim, A.K.; Morozov, S.V.; Jiang, D.; Zhang, Y.; Dubonos, S.V.; Grigorieva, I.V.; Firsov, A.A. Electric field effect in atomically thin carbon films. Science 2004, 305, 666. [CrossRef] [PubMed]

2. Yan, S.; Li, Z.S.; Zou, Z.G. Photodegradation of rhodamine B and methyl orange over boron-doped g-C3N4 under visible light irradiation. Langmuir 2010, 26, 3894. [CrossRef] [PubMed]

3. Xiang, Q.; Yu, J.; Jaroniec, M. Preparation and Enhanced Visible-Light Photocatalytic H2-Production Activity of Graphene $/ \mathrm{C}_{3} \mathrm{~N}_{4}$ Composites. J. Phys. Chem. C 2011, 115, 7355. [CrossRef]

4. Wang, Y.; Wang, X.; Antonietti, M. Polymeric graphitic carbon nitride as a heterogeneous organocatalyst: from photochemistry to multipurpose catalysis to sustainable chemistry. Angew. Chem. Int. Ed. 2012, 51, 68. [CrossRef] [PubMed]

5. Neto, A.H.C.; Guinea, F.; Peres, N.M.R.; Novoselov, K.S.; Geim, A.K. The electronic properties of grapheme. Rev. Mod. Phys. 2009, 81, 109. [CrossRef]

6. Schedin, F.; Geim, A.K.; Morozov, S.V. Detection of individual gas molecules adsorbed on grapheme. Nat. Mater. 2007, 6, 652. [CrossRef] [PubMed]

7. Watanabe, K.; Taniguchi, T.; Kanda, H. Direct-bandgap properties and evidence for ultraviolet lasing of hexagonal boron nitride single crystal. Nat. Mater. 2004, 3, 404. [CrossRef]

8. Kubota, Y.; Watanabe, K.; Tsuda, O.; Taniguchi, T. Deep Ultraviolet Light-Emitting Hexagonal Boron Nitride Synthesized at Atmospheric Pressure. Science 2007, 317, 932. [CrossRef] [PubMed]

9. Ci, L.; Song, L.; Jin, C.; Jariwala, D.; Wu, D.; Li, Y.; Srivastava, A.; Wang, Z.F.; Storr, K.; Balicas, L.; et al. Atomic layers of hybridized boron nitride and graphene domains. Nat. Mater. 2010, 9, 430. [CrossRef] [PubMed]

10. Sanchez-Sanchez, C.; Bruller, S.; Sachdev, H.; Mullen, K.; Kreig, M.; Bettinger, H.F.; Nicolai, A.; Meunier, V.; Talirz, L.; Fasel, R. On-Surface Synthesis of BN-Substituted Heteroaromatic Networks. ACS Nano 2015, 9, 9228. [CrossRef] [PubMed]

11. Bonifazi, D.; Fasano, F.; Marinelli, M.M.D.; Oubara, H.; Tasseroul, J. Boron-nitrogen doped carbon scaffolding: organic chemistry, self-assembly and materials applications of borazine and its derivatives. Chem. Comm. 2015, 51, 15222. [CrossRef] [PubMed]

12. Mazzoni, M.S.C.; Nunes, R.W.; Azevedo, S.; Chacham, H. Electronic structure and energetics of $B_{x} C_{y} N_{z}$ layered structures. Phys. Rev. 2006, B73, 073108. [CrossRef]

13. Yuge, K. Phase stability of boron carbon nitride in a heterographene structure: A first-principles study. Phys. Rev. 2009, B79, 144109. [CrossRef]

14. Ding, Y.; Wang, Y.; Ni, J. Electronic properties of graphene nanoribbons embedded in boron nitride sheets. Appl. Phys. Lett. 2009, 95, 123105. [CrossRef]

15. Shinde, P.P.; Kumar, V. Direct band gap opening in graphene by BN doping: Ab initio calculations. Phys. Rev. B 2011, 84, 125401. [CrossRef]

16. Manna, A.K.; Pati, S.K. Tunable Electronic and Magnetic Properties in $\mathrm{B}_{\mathrm{x}} \mathrm{N}_{\mathrm{y}} \mathrm{C}_{\mathrm{z}}$ Nanohybrids: Effect of Domain Segregation. J. Phys. Chem. C 2011, 115, 10842. [CrossRef]

17. Peng, Q.; De, S. Tunable band gaps of mono-layer hexagonal BNC heterostructures. Physica 2012, E44, 1662. [CrossRef]

18. Ni, M.; Wang, Y.; Yang, Q.; Zhu, W.; Tang, Q.; Li, Z. Stability and electronic properties of hexagonal boron nitride monolayer with irregular graphene domains embedded. Mod. Phys. Lett. 2014, B28, 1450144. [CrossRef]

19. Beheshtian, J.; Soleymanabadi, H.; Peyghan, A.A.; Bagheri, Z. A DFT study on the functionalization of a BN nanosheet with PCX, (PC=phenyl carbamate, $\mathrm{X}=\mathrm{OCH} 3, \mathrm{CH} 3, \mathrm{NH} 2, \mathrm{NO} 2$ and $\mathrm{CN})$. Appl. Surf. Sci. 2013, 268, 436. [CrossRef] 
20. Kan, M.; Zhou, J.; Wang, Q.; Sun, Q.; Jena, P. Tuning the band gap and magnetic properties of BN sheets impregnated with graphene flakes. Phys. Rev. 2011, B84, 205412. [CrossRef]

21. Park, H.; Wadehra, A.; Wilkins, J.W.; Castro Neto, A.H. Magnetic states and optical properties of single-layer carbon-doped hexagonal boron nitride. Appl. Phys. Lett. 2012, 100, 253115. [CrossRef]

22. Xie, Y.; Yu, H.; Zhang, H.X.; Fu, H.G. Tuning the band gaps and work functions via topology and carbon concentration: a first-principles investigation of $\mathrm{C}_{\mathrm{x}}(\mathrm{BN})_{\mathrm{y}}$ compounds. Phys. Chem. Chem. Phys. 2012, 14, 4391. [CrossRef] [PubMed]

23. Ramasubramaniam, A.; Naveh, D. Carrier-induced antiferromagnet of graphene islands embedded in hexagonal boron nitride. Phys. Rev. 2011, B84, 075405. [CrossRef]

24. Menezes, M.G.; Capaz, R.B. Half-metallicity induced by charge injection in hexagonal boron nitride clusters embedded in grapheme. Phys. Rev. 2012, B86, 195413. [CrossRef]

25. Giannozzi, P.; Baroni, S.; Bonini, N.; Calandra, M.; Car, R.; Cavazzoni, C.; Ceresoli, D.; Chiarotti, G.L.; Cococcioni, M.; Dabo, I.; et al. QUANTUM ESPRESSO: A modular and open-source software project for quantum simulations of materials. J. Phys. 2009, 21, 395502. [CrossRef] [PubMed]

26. Wang, Q.B.; Zhou, C.; Wu, J.; Lü, T.; He, K.-H. GGA+U study of the electronic and optical properties of hexagonal BN phase $\mathrm{ZnO}$ under pressure. Comput. Mater. Sci. 2015, 102, 196. [CrossRef]

27. Etienne, M.; Quach, A.; Grosso, D.; Nicole, L.; Sanchez, C.; Walcarius, A. Molecular Transport into Mesostructured Silica Thin Films: Electrochemical Monitoring and Comparison between p6m, P63/mmc, and Pm3n Structures. Chem. Mater. 2007, 19, 844. [CrossRef]

28. Monkhorst, H.J.; Pack, J.D. Special points for Brillouin-zone integrations. Phys. Rev. 1976, B13, 5188. [CrossRef]

29. Tit, N.; Peressi, M.; Baroni, S. Ab initio calculation of the band offset at strained GaAs/InAs (001) heterojunctions. Phys. Rev. 1993, B48, 17607. [CrossRef]

30. Cooper, D.R.; D’Anjou, B.; Ghattamaneni, N.; Harack, B.; Hilke, M.; Horth, A.; Majlis, N.; Massicotte, M.; Vandsburger, L.; Whiteway, E.; et al. Experimental Review of Graphene. ISRN Condens. Matter Phys. 2012, 2012, 501686. [CrossRef]

31. Nakada, K.; Fujita, M.; Dresselhaus, G.; Dresselhaus, M.S. Edge state in graphene ribbons: Nanometer size effect and edge shape dependence. Phys. Rev. B 1996, 54, 17954. [CrossRef]

32. Knittle, E.; Wentzcovitch, R.M.; Jeanloz, R.; Cohen, M.L. Experimental and theoretical equation of state of cubic boron nitride. Nature 1989, 337, 349. [CrossRef]

33. Goto, K.; Kubo, T.; Yamamoto, K.; Nakasuji, K.; Sato, K.; Shiomi, D.; Takui, T.; Kubota, M.; Kobayashi, T.; Yakusi, K.; et al. A Stable Neutral Hydrocarbon Radical: Synthesis, Crystal Structure, and Physical Properties of 2,5,8-Tri-tert-butyl-phenalenyl. Am. Chem. Soc. 1999, 121, 1619. [CrossRef]

34. Chi, X.; Itkis, M.E.; Patrick, B.O.; Barclay, T.M.; Reed, R.W.; Oakley, R.T.; Cordes, A.W.; Haddon, R.C. The First Phenalenyl-Based Neutral Radical Molecular Conductor. J. Am. Chem. Soc. 1999, 121, 10395. [CrossRef]

35. Itkis, M.E.; Chi, X.; Cordes, A.W.; Haddon, R.C. Resonating valence-bond ground state in a phenalenyl-based neutral radical conductor. Science 2002, 296, 1443. [CrossRef] [PubMed]

36. Morita, Y.; Suzuki, S.; Sato, K.; Takui, T. Synthetic organic spin chemistry for structurally well-defined open-shell graphene fragments. Nat. Chem. 2011, 3, 197. [CrossRef] [PubMed]

37. Ratera, I.; Veciana, J. Playing with organic radicals as building blocks for functional molecular materials. Chem. Soc. Rev. 2012, 41, 303. [CrossRef] [PubMed]

38. Wei, X.; Wang, M.; Bando, Y.; Golberg, D. Post-Synthesis Carbon Doping of Individual Multiwalled Boron Nitride Nanotubes via Electron-Beam Irradiation. J. Am. Chem. Soc. 2010, 132, 13592. [CrossRef] [PubMed]

39. Wei, X.; Wang, M.; Bando, Y.; Golberg, D. Electron-Beam-Induced Substitutional Carbon Doping of Boron Nitride Nanosheets, Nanoribbons, and Nanotubes. ACS Nano 2011, 5, 2916. [CrossRef] [PubMed]

40. Berseneva, N.; Krasheninnikov, A.V.; Nieminen, R.M. Mechanisms of Postsynthesis Doping of Boron Nitride Nanostructures with Carbon from First-Principles Simulations. Phys. Rev. Lett. 2011, 107, 035501. [CrossRef] [PubMed]

(C) 2016 by the authors; licensee MDPI, Basel, Switzerland. This article is an open access article distributed under the terms and conditions of the Creative Commons by Attribution (CC-BY) license (http://creativecommons.org/licenses/by/4.0/). 